\title{
Perfil Socioidentitário e Profissional Docente no Ensino Superior: Implicações na/da Relação Professor e Estudante
}

\author{
Professional and Social Identity Profiles in Higher Education: Implications \\ in/of The Teacher and Student Relationship \\ Perfil Socioidentiário Profesional en Educación Superior: Implicaciones en /de \\ la Relación Profesor y Estudiante
}

\author{
FABRÍCIO OLIVEIRA DA SILVA ${ }^{1}$
}

${ }^{1}$ Universidade Estadual de Feira de Santana

RESUMO: O artigo apresenta o perfil socioidentitário profissional de professores da Universidade Estadual de Feira de Santana - UEFS, enredando reflexões em torno da relação professor e estudante face aos processos de ensino e aprendizagem na universidade. O foco centra-se em questões inerentes às práticas educativas dos professores com vistas a compreender como a relação com os estudantes se visibiliza pelo fazer docente. O texto objetiva discutir as ações pedagógicas de professores universitários em relação ao desenvolvimento de aprendizagens logradas pelo estudante. A pesquisa é de natureza quantitativa e revela os resultados de um questionário do tipo survey, de 25 questöes, aplicado a 338 professores de diferentes áreas do conhecimento. O estudo permitiu concluir que a relação professor e estudante é fundamental para o desenvolvimento de aprendizagens. Os professores revelam que planejam aulas, que socializam tais planejamentos com os estudantes, que explicam os critérios de avaliação, inclusive os relativos à correção.

\section{PERFIL SOCIOIDENTITÁRIO PROFISSIONAL DOCENTE. RELAÇÃO PROFESSOR E ESTUDANTE. ESTRATÉGIAS DE ENSINO. PESQUISA QUANTITATIVA.}

\begin{abstract}
This article presents the professional social identity profiles for professors at the State University of Feira de Santana (UEFS). It entangles reflections around the professor-student relationship in face of the teaching and learning processes at the university. The focus is adjusted to issues inherent to the educational practices of professors, in order to understand how their relationship with students is made visible by the teaching. The text aims to discuss the pedagogical actions of university professors in relation to the development of learning achieved by the students. This work has a quantitative research nature, and reveals the results of a survey containing 25 questions, which was applied to 338 teachers from different areas of knowledge. The study has concluded that the professorstudent relationship is fundamental for the development of learning. Professors reveal that they plan classes and socialize it with students, besides, that they explain the evaluation criteria, including those ones related to correction.

PROFESSOR PROFESSIONAL SOCIAL IDENTITY PROFILE, PROFESSORSTUDENT RELATIONSHIP, TEACHING STRATEGIES, QUANTITATIVE RESEARCH.
\end{abstract}




\begin{abstract}
RESUMEN: El articulo presenta el perfil socioidentitario profesional de los profesores de la Universidad Estadual de Feira de Santana - UEFS, entrelazando reflexiones en torno a la relación docente-alumno sobre los procesos de enseñanza y aprendizaje en la universidad. El foco está en cuestiones inherentes a las prácticas educativas de los docentes para comprender cómo la relación con los estudiantes se hace visible a través de la enseñanza. El texto tiene como objetivo discutir las acciones pedagógicas de los profesores universitarios en relación con el desarrollo de los aprendizajes logrados por el alumno. La investigación es de carácter cuantitativo y revela los resultados de un cuestionario de encuesta, de 25 preguntas, aplicado a 338 docentes de diferentes áreas de conocimiento. El estudio concluyó que la relación profesor-alumno es fundamental para el desarrollo del aprendizaje. Los docentes revelan que planifican las clases, que socializan dichos planes con los alumnos, que explican los criterios de evaluación, incluidos los relacionados con la corrección.

\section{PERFIL SOCIOIDENTITARIO PROFESIONAL DOCENTE. RELACIÓN DOCENTE-ALUMNO. ESTRATEGIAS DE ENSEÑANZA. INVESTIGACIÓN CUANTITATIVA.}

\title{
Introdução
}

A relação professor e estudante na universidade é fundante para a promoção dos processos de ensino e aprendizagem, sobretudo pela viabilidade dos mecanismos de confiança que se estabelecem nessas relações. $\mathrm{O}$ estudante universitário, principalmente os que estão nos primeiros semestres de curso, precisam transpor barreiras no campo das relações universitárias, caso desejem êxito no percurso formativo que vivenciam no cotidiano da instituição. São relações múltiplas e complexas que vão desde as que se estabelecem com os colegas de turma, com os professores em sala de aula, àquelas inerentes as pessoas que lidam e atuam na coordenação de colegiados, direção de departamentos, setores outros, como bibliotecas, laboratórios, pró-reitorias, etc. Assim sendo, o estudante precisa conviver com diversas pessoas no âmbito universitário e aprender com cada uma delas a funcionalidade do ambiente acadêmico, extraindo de cada relação possibilidades de aprender e de identificar-se com o conhecimento que se produz e emerge de tais relações.

No campo educacional, em que pese a relação pedagógica entre professores e estudantes, é muito comum ouvir queixas, tanto de docentes como de discentes, de que o distanciamento entre esses sujeitos interfere nos processos de ensino e de aprendizagem. Culturalmente parece imperar a ideia de que o estudante precisa criar vínculos com a instituição, de como acadêmico e social para que ele se sinta pertencente àquele espaço e crie vínculos que passam pelas relações que ali se estabelecem. Um estudante que esteja bastante integrado à instituição revela por meio de sua postura relacional que há envolvimentos no espaço universitário tanto academicamente quanto socialmente (Tinto, 2012; Massi, 2013).

Parto, portanto, do princípio de que a configuração das dimensões relacionais e culturais da instituição, logo do professor e do estudante possibilitam que ambos estejam imbricados com os processos de ensino e de aprendizagem que aí se desenvolvem, numa perspectiva de se criar relações pedagógicas que, no caso do estudante, favoreçam a essas condições de desenvolver o senso de pertença ao espaço universitário, logo ao movimento necessário para gerar a construção de saberes. Nessa direção, a relação entre professores e alunos não deve ser unilateralizada nas expectativas de um ou de outro apenas. Se, por um lado, os professores devem desenvolver práticas que acolham os discentes em suas necessidades formativas, por outro, os estudantes devem, também, desenvolver posturas de engajamento com as ações docentes, e, consequentemente, com o espaço educativo, tendo em vista construírem o processo de filiação acadêmica.

O estudante, nesse caso, cria condição relacional com seus professores e com o espaço educativo, de modo a possibilitar a sua filiação acadêmica, criando, nessa tessitura relacional, condições exequíveis de aprender o ofício de ser estudante autônomo e engajado. (Coulon, 2008). Isso implica que o estudante possa gerar condições para manter perene as relações que estabelecem com os professores na universidade.

De igual modo, os professores devem criar condições relacionais com os estudantes, com o objetivo de que estes possam compreender a dinâmica do trabalho educativo na universidade, sobretudo pela clareza que deve se instaurar nos princípios pedagógicos de que lançam mão os professores para desenvolver aprendizagens. Nessa direção, a relação pedagógica que se principia na relação professor e estudante aponta para uma condição de que o discente possa desenvolver filiação acadêmica, com condições de compreender as funcionalidades das 
regras institucionais, e de igual modo, aprender o ofício de ser estudante, mobilizando os professores a engajarem-se, cada vez mais com o ofício de ser professor. Isso implica reconhecer que a relação entre professores e estudantes desenvolvem condições de aprendizagens num processo de ambivalência, em que tanto se engajam e aprendem o professor e o estudante.

O professor, muitas vezes, se vê distante dos estudantes, desenvolvendo uma prática educativa que se fecha em si mesma, mobilizada pela necessidade que o docente se impõe de ministrar o conteúdo, e assim cumprir o programa de disciplina. Nessa seara, se o estudante aprende ou não, passa a ser uma preocupação a menos, em algumas situações. Há ainda de se considerar tipificações do ensino universitário, ancorado em certos princípios que fazem a aula na universidade fluir por meio de palestras e exposições orais, que pouco possibilitam a interação professor e aluno. Ademais, a docência numa universidade é caracterizada por uma quantidade de atividades inerentes a esse segmento de ensino. Em determinadas situações, o professor universitário se sente inseguro em relação ao papel de mediador do processo de questionamento, reflexão e ressignificação de conteúdos e, portanto, sente-se inseguro, também, em relação à sua condição de ajudar os alunos a desenvolverem a capacidade de pensar e argumentar, que a nova realidade exige (Santos; Soares, 2011).

As práticas educativas de professores na universidade devem favorecer condições para que os estudantes possam relacionar-se efetivamente com colegas, com os próprios professores e com os funcionários. É preciso, no entanto, reconhecer as particularidades de cada instituição de acordo com o modelo organizacional e pedagógico adotado, face às peculiaridades de cada sujeito no âmbito das relações que se estabelecem. Nesse sentido, a organização do trabalho pedagógico que professores estabelecem no seu fazer educativo torna-se evidência de processos de engajamento e de filiação educativa que os estudantes desenvolvem, tendo como consequência êxito nos processos de aprendizagem na universidade.

Com o objetivo de discutir as ações pedagógicas de professores universitários no que tange ao desenvolvimento de aprendizagens logradas pelo estudante, o presente estudo traz à baila os resultados de uma pesquisa desenvolvida no âmbito do Núcleo de Estudos e Pesquisas sobre Pedagogia Universitária - NEPPU. O estudo buscou mapear o perfil socioidentitário de docentes que atuam em diferentes áreas do conhecimento na Universidade Estadual de Feira de Santana - UEFS, bem como apresentar os resultados quantitativos a partir de quatro dimensões que transversalizam o fazer pedagógico dos professores. Nessa perspectiva, analisam-se questões inerentes a procedimentos que professores utilizam para elaboração do planejamento pedagógico, para o desenvolvimento de estratégias de ensino, de produção e correção da avaliação da aprendizagem, bem como de questões relativas à formação continuada, excetuando-se as formações de natureza stricto sensu.

Apesar de ser uma pesquisa que se desenvolve com foco na relação professor e estudante na universidade, mapeando o que ambos dizem sobre os processos de ensino e aprendizagem, o presente estudo foca nas respostas dadas por 338 professores participantes da pesquisa. O texto está dividido em quatro outras seções, além da introdução, na qual se apresentou a problemática e o objetivo do estudo. Assim sendo, na segunda seção do texto dedica-se a apresentar a tessitura metodológica em que se desenvolveu a presente pesquisa, com foco especial para o processo de construção e organização do questionário. Na terceira, de modo suscinto, apresentam-se os resultados do perfil socioidentitário e profissional dos participantes. Na quarta seção, abordam-se aos resultados encontrados no questionário, agrupando-se o movimento de análise considerando duas dimensões, quais sejam: planejamento pedagógico e avaliação da aprendizagem. Por fim, mas não menos importante, tecem-se as considerações finais do trabalho. 


\section{Percurso Metodológico}

A pesquisa se inscreve na epistemologia de natureza quali-quanti, segundo o que preconiza Creswell (2007), por considerar que este tipo de pesquisa ancora características tanto da pesquisa quantitativa, como da qualitativa, gerando um novo modo de realizar estudos em que pese a viabilidade de tanto se trabalhar com os dados numéricos, quanto com os textos que podem ser produzidos pelos colaboradores de uma pesquisa. Cabe ressaltar que o recorte para esse trabalho tem uma maior centralidade na epistemologia da pesquisa quantitativa, em que se apresentam as porcentagens considerando frequência de ocorrências nas respostas dos colaboradores, valorizando a análise a partir das maiores ocorrências encontradas.

Como dispositivo de recolha de informações, a pesquisa se desenvolveu a partir de um questionário elaborado por um grupo de pesquisadores e estudantes da docência universitária, que desenvolvem a pesquisa intitulada Relação professor e estudante na universidade ${ }^{1}$. Trata-se de um questionário construído pelas relações dialógicas tecidas por professores e estudantes no âmbito do NEPPU. Assim sendo, a construção do instrumento teve como base as acontecências da sala de aula na universidade, com foco nas práticas educativas de professores face ao desafio de gerar condições de aprendizagem pelas relações pedagógicas que docentes estabelecem com os estudantes na universidade. O questionário foi aplicado durante o mês de abril de 2020, através da plataforma Google Forms. Nessa dinâmica, criou-se um link para acesso ao questionário, o qual foi enviado, por e-mail, para todos os diretores de departamentos da universidade, com solicitação de que se replicasse a todos os professores lotados em cada departamento. De um total de 982 professores da instituição, 338 acessaram e responderam as questões, o que representa uma amostra de um terço do universo de docentes da universidade.

Dito isso, obteve-se a resposta de 338 professores de diferentes áreas do conhecimento da Universidade Estadual de Feira de Santana, que voluntariamente acessaram o questionário e responderam as 33 questões, sendo 8 inerentes ao perfil socioidentitário e profissional, e 25 relativas a situações pedagógicas vivenciadas pelos professores na universidade. O questionário foi elaborado considerando situações relatadas pelos professores e estudantes pesquisadores no que tange às vivências relacionais pedagógicas no âmbito de situações do planejamento, da produção de estratégias de ensino, da avaliação educacional e dos investimentos que docentes fazem na formação continuada. Com relação aos aspectos do perfil socioidentitário e profissional, as opções buscaram mapear idade, sexo, cor/raça, tipo de vínculo institucional, regime de trabalho, anos de atuação na docência no Ensino Superior e anos na docência em outros níveis.

Estruturadas conforme os princípios de uma escala do tipo Likert, as questões foram compostas de afirmações, seguida das alternativas: nunca, às vezes, frequentemente e sempre. Diante dessas quatro opções, o participante só poderia marcar uma. Essa é uma escala que é bastante útil para analisar o comportamento das pessoas diante de um dado fenômeno. No campo da educação, é uma escala de referência para se compreender os níveis de frequência com que os professores se comportam diante de situações de natureza pedagógica, e no caso da pesquisa em tela, também de natureza relacional. As afirmações se originaram, no presente estudo, de crenças comportamentais que são comumente visibilizadas no âmbito das salas de aula na universidade. Assim, as crenças revelam as atitudes que os professores adotam na relação com o estudante diante do desafio de ensinar e de possibilitar aprendizagens.

Nessa direção analítica, a atitude é uma característica das pessoas que faz referência ao conjunto de crenças sobre algo e sua resposta em relação a isso (Thurstone, 1928). Aferir uma atitude pedagógica no campo da docência universitária se torna importante pelo fato de que este conhecimento é útil na compreensão do comportamento relacional que professores e estudantes estabelecem na universidade, e de como isso tem relação com os processos de ensino e de aprendizagem. É uma interessante pista para se desenvolver entendimentos sobre as formas como professores e estudantes tomam decisões para ensinar e aprender na universidade, revelando conhecimento do modo como se organizam pedagogicamente as relações entre esses sujeitos no âmbito da docência universitária.

\footnotetext{
${ }^{1}$ Pesquisa financiada pela Chamada Universal MCTI/CNPq nº28/2018, aprovada pelo Comitê de Ética da UEFS, através do parecer $n^{\circ}$ 3.413.070. O estudo tem parceria com o Núcleo Interdisciplinar de Estudos sobre Desigualdades Sociais em Saúde (NUDES), da Universidade Estadual de Feira de Santana (UEFS).
} 


\section{Sobre o perfil identitário e socioprofissional dos participantes}

A Universidade Estadual de Feira de Santana foi autorizada pelo Decreto Federal no 77.496 no ano de 1976, reconhecida pela Portaria Ministerial no 874/86 de 19-12-86 e Recredenciada pelo Decreto Estadual $n^{\circ}$ 9.271 de 14-12-20042. Trata-se de uma instituição pública do Estado da Bahia que conta com um quadro de 982 docentes lotados em nove diferentes departamentos que integram o campus universitário. Desse universo de professores, participaram 338, sobre os quais traçamos o perfil com base nos dados do questionário.

No que tange a categoria idade, tem-se $45 \%$ dos professores com idade acima de 50 anos. Na faixa entre 46 a 50 anos registram-se outros 15\%. Nesse sentido, vemos que $60 \%$ dos professores que compõem esse estudo têm mais de 46 anos. Com menos de 30 anos, registram-se apenas $2 \%$ dos respondentes.

Predomina o gênero masculino, que se visibiliza em 58\% dos respondentes. Esse dado indica que na docência universitária, a predominância ainda é de homens, o que se confirma pelos dados censitários do Instituto Nacional de Estudos e Pesquisas Educacionais Anísio Teixeira - INEP³ que aponta a predominância de homens no Ensino Superior, em se considerando a soma total de docentes nas diferentes regiões e esferas administrativas. Vale destacar que o censo INEP subdivide a análise do quadro de docentes, considerando as categorias administrativas das Instituições de Ensino Superior - IES. Assim sendo, as informações sobre docentes consideram a lotação em universidades, faculdades, centro universitários e institutos federais.

Nesse sentido, e considerando-se o total de docentes que atuam no Ensino Superior no Brasil temos $53,7 \%$ de homens. Observando-se o número de docentes na rede pública em todo território nacional, também predomina o gênero masculino, com um total de 54,8\%. Em escala semelhante, ao se considerar as universidades estaduais brasileiras os homens também predominam com um quantitativo de 52,8\%. Ao se considerar o quantitativo de docentes do sexo masculino que atuam em universidades estaduais no Nordeste, observa-se, um fenômeno contrário, pois a predominância é de mulheres, chegando a $52 \%$. Também com predomínio do gênero feminino, tem-se o total de 51,5\% no cenário baiano, considerando todas as redes de ensino. Analisando os dados da Bahia na rede pública, tem-se, também, o predomínio de mulheres, com $51 \%$. Ao se analisar os dados relativos aos docentes que atuam nas universidades estaduais, o quantitativo de mulheres é também superior, chegando a $54 \%$. Portanto, no que tange ao sexo, os dados da UEFS contrariam o que se verifica na tendência local do estado e da região Nordeste, uma vez que nesses o predomínio é de mulheres. Por outro lado, o quantitativo de 58\% de homens evidencia uma tendência que se observa nos dados gerais do Brasil, em que os homens ainda são maioria na docência universitária.

Ao se considerar uma tendência local de crescimento das mulheres na docência universitária, destaca-se na UEFS há necessidade de que as mulheres ocupem os cargos da profissão docente, pois $58 \%$ indica um número elevado de homens, o que demarca, até mesmo superior aos dados nacionais, que apontam 53,7\% de homens, um desequilíbrio entre homens e mulheres na universidade. De acordo com o que defendem Teixeira e Freitas (2014), apesar de no Brasil, os homens serem maioria numérica nas instituições de ensino superior, tanto em instituições públicas quanto privadas, é notório um processo de feminização de postos de trabalho no Ensino Superior atrelado a perda de status e de poder aquisitivo, apresentando processo de proletarização da docência nesse nível.

No entanto, os dados da UEFS ainda evidenciam que a relação de poder entre os gêneros impera, e cria uma situação que faz predominar a presença de maioria de homens na instituição, o que pode ser explicado pelas ideias de Teixeira e Freitas (2014) que apontam para a existência de micros espaços de atuação de professores, em se considerando as relações de gênero. Isso sugere que as relações de poder existentes entre os gêneros fazem com que os homens dominem não apenas a área de estudos, mas também os maiores cargos, sob a hipótese de que as próprias mulheres são agentes da discriminação, situação que, segundo as autoras, reproduz os valores patriarcais e desencoraja mulheres a se presentificarem em alguns espaços na docência universitária que ainda são ocupados por homens.

\footnotetext{
2 Informações retiradas da página oficial da instituição, disponível no endereço: http://www.uefs.br/modules/conteudo/conteudo.php? conteudo=12

3 Informações disponíveis no site: http://portal.inep.gov.br/web/guest/sinopses-estatisticas-da-educacao-superior. Acesso em 8 ago. 2020.
} 
Considerando o perfil profissional pela identificação de cor/raça dos professores, visibiliza-se que $44 \%$ se identificam como pardos e $41 \%$ como brancos. Apenas $11 \%$ dos participantes se identificam como pretos, o que revela que os participantes pouco se autodeclaram pretos. Cabe ressaltar que esse campo foi estruturado com cinco opções para escolha dos respondentes. Assim as opções foram indígena, preto, pardo, amarelo e branco. Havia uma opção outros, em que o participante escreveria sobre essa opção. Nesse aspecto, observa-se que um professor escreveu que não concordava com nenhuma das opções. Uma professora registra o termo parda, e diz que é assim que está na certidão dela. Uma outra escreve mestiça e por fim, há uma identificação informando que a raça é uma mistura de indígena, preto e pardo.

Nesse aspecto, é interessante notar a acentuada porcentagem de pessoas na instituição de se autodeclaram brancas. Vale lembrar que se trata de uma universidade que se localiza no território do portal do sertão, no interior baiano, em que a presença de pretos e pardos é proeminente, conforme dados do Censo Instituto Brasileiro de Geografia e Estatística - IBGE/2010 que apontam que na Bahia 17\% da população se auto declara preta, enquanto que parda se autodeclaram $59 \%$ da população. Já como branca, tem-se apenas $22 \%$ de pessoas que assim se autodeclaram. Analisando-se os dados de Feira de Santana, verifica-se que apenas 19\% de pessoas se auto declaram brancas, $23 \%$ pretas e $55 \%$ pardas. Se compararmos os dados da população de respondentes da UEFS, vemos que há uma "branquitude" que impera, chegando a índices que representam mais que o dobro dos que se declaram brancos no município, e quase o dobro do que se autodeclaram brancos no estado. Assim a UEFS tem uma significativa parcela de $41 \%$ de professores que se auto declaram brancos, e a esse dado se some o fato se ter $58 \%$ de homens. Tem-se, portanto, um perfil identitário que aponta para uma caracterização em que os sujeitos do sexo masculino são maioria, e nessa parcela há um considerável número de sujeitos que se autodeclaram brancos. Isso sugere que, em se considerando o perfil identitário dos professores, no que tange às variáveis sexo e raça/cor, na UEFS tem-se uma característica em que se visibiliza significativos números de sujeitos do sexo masculino e de cor branca.

No que tange ao tipo de vínculo com a instituição, tem-se um total de $92 \%$ do quadro de professores efetivos. Destes, $60 \%$ são de dedicação exclusiva à instituição e $43 \%$ são professores com mais de 20 anos de trabalho na docência no Ensino Superior. Dos 338 professores, $35 \%$ nunca tiveram experiência na docência na Educação Básica e dos 65\% que já atuaram na Educação Básica, 30\% tiveram menos de 5 anos de experiência nessa modalidade de ensino.

Esses dados evidenciam que se tem um quadro de professores com significativa experiência na docência universitária, com dedicação exclusiva à universidade, o que indica a condição de que em média $60 \%$ dos docentes desenvolvem, pela exigência da carga horária, atividades de pesquisa e/ou extensão na universidade. Por outro lado, chama a atenção o quantitativo de docentes que nunca experienciaram a docência na Educação Básica, aprendendo a ser professor nas próprias itinerâncias formativas da universidade. 


\section{Práticas em torno do planejamento pedagógico}

Planejar as ações pedagógicas constitui uma das práticas relevantes da/na docência universitária. Tal postura indica que o docente faz reflexões em torno de seu trabalho pedagógico, preparando-o sequenciada e ordenadamente todo o engendramento que desenvolverá para promover a atividade de ensino com vistas ao desenvolvimento de aprendizagens nos estudantes. Apresentar o plano de curso aos estudantes indica um movimento relacional que professores estabelecem com os estudantes, criando a partir daí situações em que a atividade pedagógica se coloca como centro das reflexões educativas que se desenvolverão, ao longo do trabalho docente. Geralmente, é no primeiro encontro com os estudantes que os professores apresentam os planos de curso.

Com o desenvolvimento do trabalho pedagógico, os docentes passam a conviver com as dificuldades dos estudantes, fato que demarca modos de desenvolver estratégias e ações pedagógicas que levem em consideração tais dificuldades para empreender alterações no planejamento, logo criar metodologias, estratégias e ações que se estruturem com foco na condição de auxiliar o estudante em sua aprendizagem.

As cinco primeiras questões da pesquisa evidenciam situações relacionadas ao planejamento do professor, bem como sobre o fato dele considerar as dificuldades dos estudantes para modificar o planejamento e criar estratégias de ensino diferenciadas. Ao analisar os dados, observa-se que é uma tendência de os professores afirmarem que sempre realizam apresentação do plano aos estudantes, bem como durante as aulas, dedicam tempo para dirimir dúvidas dos estudantes. Os gráficos 1 e 2 ilustram esses resultados.

Gráfico 1 - Apresenta plano de disciplina

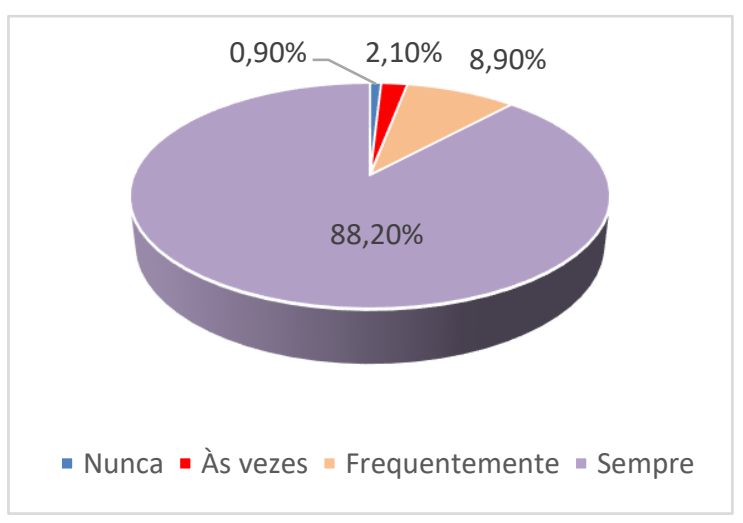

Fonte: Elaborado pelo autor (2020).
Gráfico 2 - Disponibiliza tempo para dirimir dúvidas

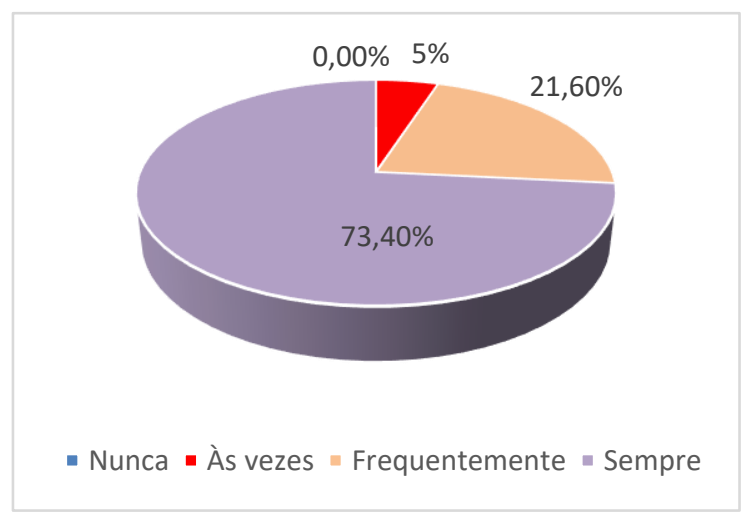

Fonte: Elaborado pelo autor (2020).

Apresentar o plano de disciplina que aparece com grande evidência de que sempre isso é feito por parte dos professores não indica necessariamente que essa ação esteja diretamente relacionada com o fato de se considerar as dificuldades dos estudantes para modificar o plano. Ao se perguntar aos professores sobre se eles modificam o seu planejamento para ajustá-lo ao ritmo e às dificuldades da turma, apenas $40 \%$ dos respondentes afirmam que sempre o fazem. Tal situação indica que, apesar de boa parte, $43 \%$, afirmar que frequentemente faz ajustes no plano, muitos professores priorizam o desenvolvimento do plano em detrimento de ajustá-lo para atender às necessidades formativas dos estudantes.

De certo modo, o planejamento deve congregar as destrezas do professor, seu conhecimento teórico em empírico sobre aquilo que se ensina, mas sobretudo deve considerar a problemática do contexto social em que atua. Assim sendo, a realidade dos estudantes, o contexto em que se encontram deve ser levado em consideração para a produção de um planejamento que seja funcional e que atenda às necessidades formativas dos estudantes. Segundo Libâneo (2001, p. 22), o planejamento tem grande importância por tratar-se de "um processo de racionalização, organização e coordenação da ação docente, articulando a atividade escolar e a problemática do contexto social". Nesse sentido, a realidade educacional precisa ser considerada para que haja ajustes no 
planejamento e se garanta a exequidade do plano pedagógico face às necessidades formativas dos estudantes na universidade.

Defendo a necessidade de elaboração do planejamento a partir das dificuldades dos estudantes. Oliveira (2007, p. 21) defende que

[...] o ato de planejar exige aspectos básicos a serem considerados. Um primeiro aspecto é o conhecimento da realidade daquilo que se deseja planejar, quais as principais necessidades que precisam ser trabalhadas; para que o planejador as evidencie faz-se necessário fazer primeiro um trabalho de sondagem da realidade daquilo que ele pretende planejar, para assim, traçar finalidades, metas ou objetivos daquilo que está mais urgente de se trabalhar.

Para tanto, é preciso que o professor na universidade não perca de vista a necessidade de criar relações pedagógicas com os estudantes com o objetivo de que possa conhecer a realidade dos seus alunos, a partir de um diagnóstico que favoreça a ele conhecer algumas das dificuldades apresentadas pela turma, e a partir daí, adequar sua metodologia e criar condições de que a aprendizagem se efetive nas necessidades dos estudantes. Nesse contexto, é de bom tom que o material didático seja, também, produzido em função das necessidades e dificuldades dos estudantes. A esse respeito, perguntou-se ao participante se ele seleciona o material didático em função das dificuldades dos seus alunos. O gráfico 3 ilustra os resultados encontrados.

Gráfico 3 - Seleciona material didático em função das dificuldades dos estudantes

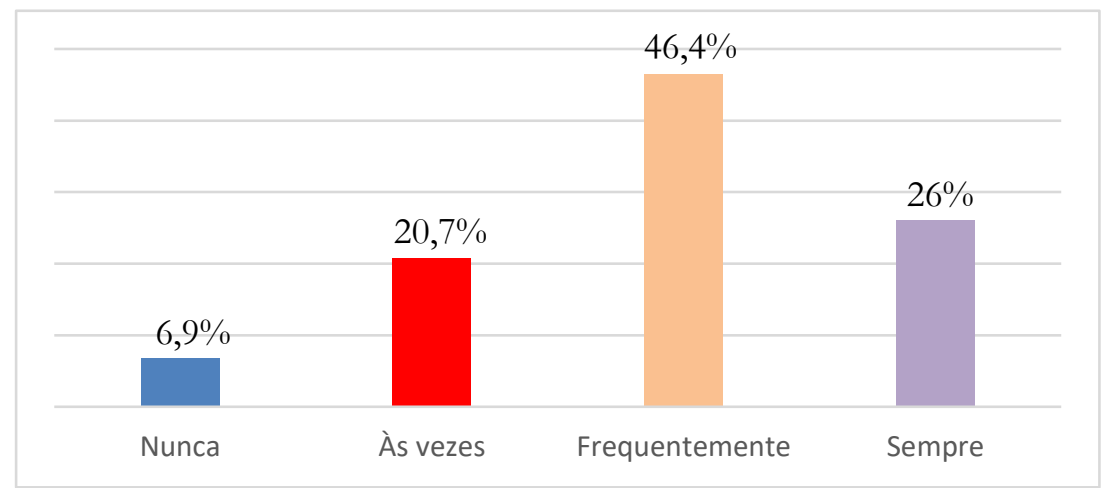

Fonte: Elaborado pelo autor (2020).

Os resultados sugerem que apesar $26 \%$ dos professores informarem que sempre selecionam materiais didáticos em função das dificuldades dos estudantes, há um considerável número de professores que dizem fazer frequentemente tal seleção de materiais. Somando-se o quantitativo dos que sempre e frequentemente selecionam materiais em função das dificuldades dos estudantes, temos um total de $73 \%$. Tal dado sugere que são necessariamente as dificuldades dos estudantes a centralidade para o processo de seleção de materiais didáticos. Há, contudo, uma evidência de que a prática educativa dos docentes leva em consideração a relevância das características do material didático para gerar condições de aprendizagem nos estudantes a partir das dificuldades que estes revelam.

No entanto, há situações em que nunca os professores consideram tal questão, o que na realidade da instituição pode ser um indicador de que alguns professores ou não conhecem as realidades e dificuldades dos estudantes, e/ou optam por priorizar o próprio material em função de se garantir a qualidade do ensino pela própria qualidade do material e não, necessariamente, pelas condições e necessidades de aprendizagem dos estudantes.

$\mathrm{Na}$ pertinência de buscar entender o lugar dos conhecimentos prévios dos estudantes para se gerar a produção de novos conhecimentos, a pesquisa buscou mapear a informação em torno da prática dos professores ao considerarem o conhecimento prévio dos estudantes para desenvolverem o ensino na universidade. Pozo e Mateos (2009) numa discussão sobre como os professores podem auxiliar os estudantes a aprender a aprender, 
discorrem sobre alguns princípios fundamentais para que os professores possam possibilitar condições de que haja aprendizagem ancorada em princípios da autonomia estudantil. Um dos princípios de que tratam os referidos autores incide nos conhecimentos prévios dos estudantes, que são aqueles sobre os quais os estudantes partem para construir novos conhecimentos.

Aprender a aprender significa, para os estudantes, uma condição de partir do que sabem para ancorar novos conhecimentos, num movimento reflexivo e progressivo em que as novas ideias se fundamentam a partir das que já existem em sua estrutura cognitiva. Para os professores, aprender a aprender converte-se em um aprender a ensinar que significa a destreza de considerar os conhecimentos prévios dos estudantes para gerar reflexões que partam de tais conhecimentos, criando condições didáticas que se efetivem numa estrutura progressiva do desenvolvimento de aprendizagens, em que o novo conhecimento se produz sempre de um conhecimento já sabido pelos estudantes.

Ao se analisar os dados da questão que aborda o fato de os professores considerarem o conhecimento prévio dos estudantes para introduzir um novo conhecimento, depara-se com um dado interessante, em que o conhecimento prévio parece ser fundamental para consolidar práticas que possibilitem a aprendizagem como asseveram Pozo e Mateos (2009). Sobre tal temática, 44\% dos professores afirmam que sempre o fazem e $40 \%$ informam fazê-lo frequentemente. Assim sendo, $84 \%$ dos participantes revelam uma disposição dialógica de apreensão dos conhecimentos prévios dos discentes, a fim de construir percursos educativos que partam de tais conhecimentos. Isso é um indicativo de que as relações pedagógicas se estabelecem de modo que os professores partem do princípio de que os estudantes possuem um conhecimento prévio e que ele é necessário para se gerar condições de aprendizagem de novos assuntos e temáticas. São os conhecimentos que os sujeitos já portam, necessários e essenciais para se criar uma estrutura de aprendizagem de novos conhecimentos.

O conhecimento prévio conceituado por Ausubel, Novak e Hanesian (1980) é aquele caracterizado como declarativo, que está na base do conhecimento que o estudante já logrou em suas experiências formativas. Segundo Novak e Gowin (1996), o conhecimento prévio é o conhecimento ou consciência de algum objeto, caso ou ideia, mas que pressupõe um conjunto de outros conhecimentos, afetivos e contextuais, que igualmente configuram a estrutura cognitiva prévia do estudante que aprende. Esse movimento implica em se reconhecer que a estrutura cognitiva gera condições para que o aprendente crie para si condições de atribuição de sentido para aquilo que ele aprende, a partir do que já conhecia. Nessa direção, a teoria da aprendizagem significativa concebe o conhecimento prévio do sujeito como referência explicita para a produção de novas aprendizagens, logo como uma varável relevante e a ser considerada na organização do ensino. Segundo Ausubel, Novak e Hanesian (1980, p. 137), "se eu tivesse que reduzir toda a psicologia educacional a um único princípio, diria isto: o fator singular que mais influencia a aprendizagem é aquilo que o aprendiz já conhece. Descubra isso e ensineo de acordo". 


\section{Práticas com a avaliação da aprendizagem}

No que tange às discussões sobre a avaliação da aprendizagem, há diversas perspectivas de se conceber o ato de avaliar e, sobretudo, sobre como avaliar os estudantes na universidade. Embora a pedagogia contemporânea defenda uma concepção de avaliação como instrumento de emancipação, no cotidiano educativo universitário prevalecem, em determinadas situações, práticas avaliativas com ênfase na apreensão dos resultados que serão obtidos pelos estudantes e não, necessariamente, com foco nos processos de construção de sua aprendizagem.

$\mathrm{Na}$ relação pedagógica entre professores e estudantes na universidade busca-se desenvolver ações avaliativas que transponham a ideia de que uso dos resultados das avaliações encerre-se na identificação e no registro de símbolo, geralmente numérico, do valor pelo qual se mensura a aprendizagem do discente. Apesar de predominantemente serem símbolos que se representam por meio de notas, são o que os professores lançam mão para expressarem o valor atribuído referente aos resultados que evidenciam as aprendizagens dos estudantes, encerrando-se aí o ato de avaliar que, como revela Luckesi (2005) quando diz que o valor é concedido pelo professor ao aprendido pelo estudante, é registrado e, definitivamente, o aluno permanecerá nesta situação, o que equivale a ele estar determinantemente classificado.

No âmbito da docência universitária, em que a relação professor e estudante transpõem a ideia de ter uma nota que represente o que o estudante aprendeu ao longo do processo formativo, é mister considerar que a avaliação seja constituída por momentos e movimentos dialógicos, reflexivos, oriundos da prática do professor, mas com participação efetiva do estudante no processo avaliativo. Essa participação implica em reconhecer a autonomia do estudante universitário para considerar as diferentes abordagens e instrumentos avaliativos, pelos quais a avaliação ocorre na universidade. Nesse sentido, e considerando a relação dialógica entre professor e aluno na docência universitária, o momento de avaliar a aprendizagem do estudante não deve ser o ponto de chegada da prática do professor, mas uma oportunidade de parar e observar se a caminhada está ocorrendo com a qualidade previamente estabelecida para esse processo de ensino e aprendizagem para retomar a prática pedagógica de forma mais adequada, uma vez que o objeto da ação avaliativa, no caso a aprendizagem, é dinâmico, e, com a função classificatória, a avaliação não auxilia o avanço e o crescimento para a autonomia (Luckesi, 2005).

A partir das considerações até aqui expostas, entende-se que uma das temáticas centrais que transversalizam a relação professor e estudante na universidade, sem dúvida, diz respeito ao processo de avaliação da aprendizagem. Parte-se, nesse estudo, do princípio de que a avaliação não se reduz à verificação ou a checagem. Segundo Silva, Ribeiro e Almeida (2018)

\footnotetext{
Entender, propor e gerenciar a avaliação da aprendizagem levando em consideração a sua complexidade tem se colocado como um desafio que professores universitários se lançam na tentativa de transpor a prática de avaliação enquanto verificação da aprendizagem. Avaliar na concepção de aprendizagem construtivista do paradigma emergente pressupõe uma construção dialógica entre diferentes sujeitos professor e aluno que envolve um paradigma que se assenta na ideia de construção de processos cognitivos que põem em evidência a ação reflexiva de construção de saberes, logo, de desenvolvimento de aprendizagens (Silva, Ribeiro \& Almeida, 2018, p. 666-667).
}

Tendo a prática avaliativa como um princípio de construção dialógica que se evidencia na relação entre professores e estudantes na universidade, as questões inerentes a dimensão da avaliação da aprendizagem focalizaram princípios da relação dialógica entre professor e aluno no que concerne às ações dos professores em discutir com os estudantes a respeito da tessitura dos instrumentos avaliativos, explicitar os critérios de correção das avaliações e, por fim, incluir comentários sobre as respostas dos alunos, no momento da devolução dos instrumentos.

Nessa perspectiva, ao se apresentar ao professor a consigna: Você discute como serão os instrumentos de avaliação da aprendizagem, obteve-se um total de $61 \%$ dos respondentes afirmando que sempre discutem. $27 \%$ marcaram a opção frequentemente. Isso indica que a avaliação tem sido palco de reflexões da prática educativa dos professores, engendradas nas relações dialógicas com os estudantes. Esse resultado é simétrico com os dados inerentes à ação do professor apresentar o plano de ensino aos estudantes, uma vez que a grande 
maioria apresenta o plano, no qual se inserem os critérios e instrumentos de avaliação a serem adotados. No entanto não fica claro nos dados do survey qual a participação do estudante nesse processo dialógico e de construção dos instrumentos. Não é possível, por exemplo, inferir que os instrumentos de avaliação são construídos a partir das contribuições dos estudantes, ou ainda se os instrumentos são elaborados a partir das necessidades formativas dos educandos.

Por outro lado, os dados elucidam a disposição dos docentes em explicitar os critérios de avaliação e, portanto, de evidenciar o modo como os instrumentos se estruturam na prática educativa do professor. No que tange aos critérios de correção das avaliações, os resultados mostram uma tendência de que os professores alimentam a preocupação em deixar explícito quais são os critérios que utilizam para tal fim. Entretanto, não há indicativo de que esses critérios sejam negociados e tecidos nas relações dialógicas com os estudantes.

Assim, explicitar os critérios de correção das avaliações, ainda que seja uma prática relevante e necessária para o aprendente, pois a avaliação se fundamenta em objetivos que devem estar claros para professores e estudantes, não significa que os critérios sejam construídos nos/pelos diálogos com os estudantes. Mas há de se evidenciar o aspecto positivo de se explicitar os critérios, ao se observar que a grande maioria dos professores adota sempre essa prática. Os dados são ilustrados no gráfico a seguir.

Gráfico 4 - Explicita critérios de correção das avaliações

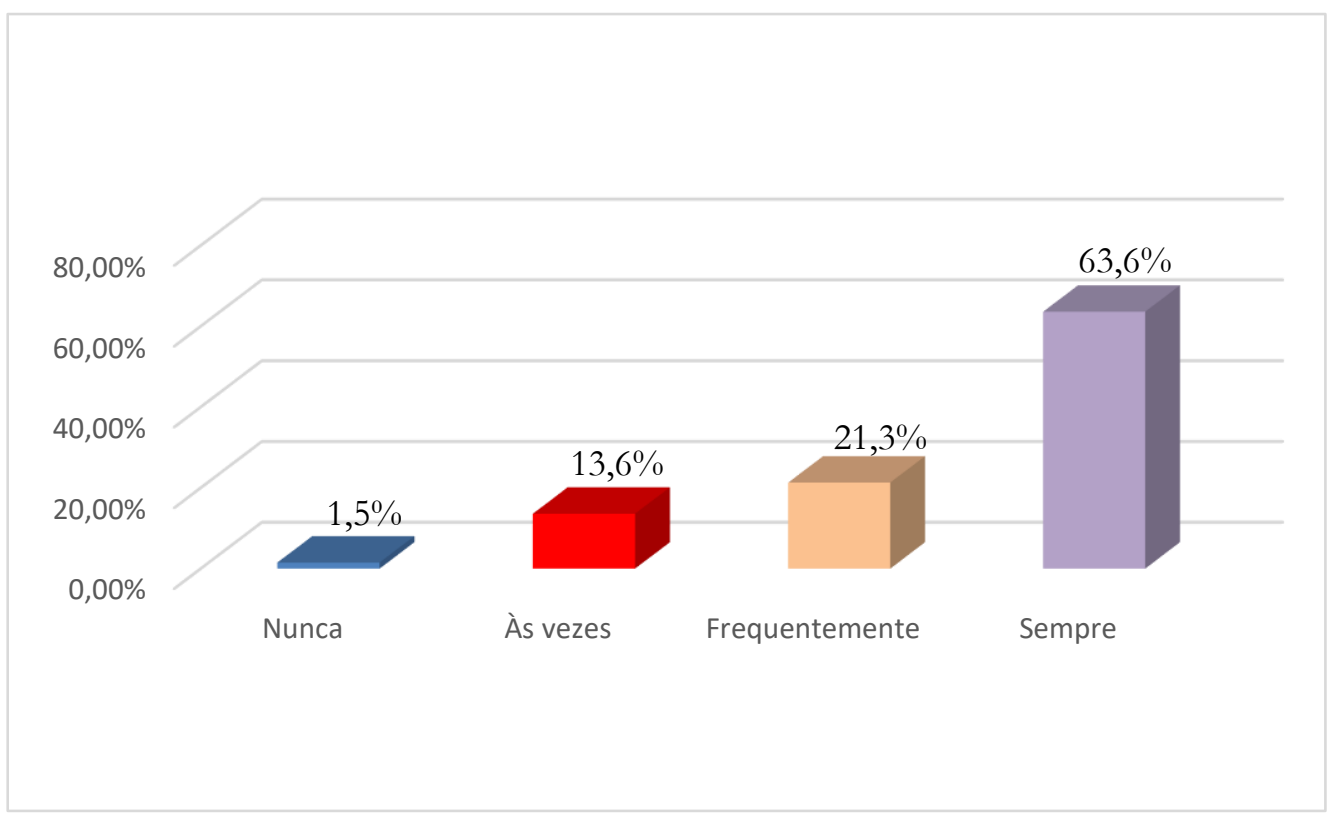

Fonte: Elaborado pelo autor (2020).

Pelo exposto no gráfico, $64 \%$ dos participantes afirmam que sempre explicitam os critérios de correção das avaliações e outros $21 \%$ dizem fazer isso frequentemente. Trata-se de uma estratégia que traz para o cerne das práticas educativas uma relação pedagógica em que se evidenciam os procedimentos avaliativos, gerando clareza ao processo de avaliar na universidade. Isso sugere que há evidências de que "na prática universitária, os professores têm lançado mão de estratégias de ensino que tenham como princípio fundante o desenvolvimento e efetivação da aprendizagem dos estudantes (Silva, Ribeiro \& Almeida, 2018, p. 667). Nesse sentido, uma das estratégias é jogar luz sobre a regra do jogo avaliativo, em que professores e estudantes tenham conhecimento sobre a tessitura da avaliação, bem como dos objetivos que os docentes projetam para os estudantes, dando a estes a condição de conhecer os critérios adotados no ato de avaliar.

Nessa dimensão, buscou-se, ainda, verificar se na devolução das avaliações os professores registram seus comentários, dando aos estudantes retorno sobre seus desempenhos. Nesse interim, os dados revelam que $48 \%$ dos professores fazem isso sempre e que $32 \%$ frequentemente. Portanto, os dados sugerem que o ato de avaliar 
é acompanhado de retorno do desempenho, dando aos estudantes, a condição de conhecerem, mais qualitativamente, como se desempenharam nas travessias avaliativas na universidade.

Os dados evidenciam a existência considerável de práticas do feedback. Segundo Brookhart (2008) o retorno que os professores dão aos estudantes por meio de comentários nos instrumentos avaliativos é fundamental para o progresso das aprendizagens dos estudantes. Tal ação contribui para que haja condições de reflexão em torno do desenvolvimento que o próprio estudante constrói para aprender, bem como para pensar sobre o caminho e as estratégias de que lançou mão para evidenciar aprendizagens por meio de suas respostas. Nessa seara, o feedback contribui para que o estudante compreenda os percursos que o possibilitaram acertar ou errar a resposta e, com isso, desenvolver processos de autonomia reflexiva diante das práticas avaliativas que os professores desenvolvem na universidade. No entanto, cabe destacar que os dados não permitem discutir o tipo de comentário e nem a funcionalidade deste no processo avaliativo do estudante. Esses dados poderão ser alcançados em uma fase de pesquisa qualitativa, em que os professores possam esclarecer como fazem e os objetivos que empreendem para realizar tais comentários nas avaliações dos estudantes. 


\section{Considerações finais}

A relação professor e estudante na universidade tem sido debate que se presentifica nos estudos em que a ideia seja compreender como a relação entre quem ensina e quem aprende na universidade gera condições efetivas de aprendizagem. Atribui-se aos professores a ideia de sucesso educacional, com a crença de que são esses os profissionais que dominam a arte de ensinar, e que, portanto, precisam conduzir o processo de ensino com destreza, competência e profissionalismo, com vistas a gerar resultados efetivos de aprendizagens nos estudantes. No entanto, é preciso entender que, principalmente no contexto universitário, a relação pedagógica se constitui como ponto de centralidade de práticas que se efetivam na relação com o outro. $\mathrm{O}$ ensino universitário é destinado para jovens e adultos, logo para pessoas com condições de mediarem e de desenvolverem o processo de ensino e de aprendizagem de modo autônomo e eficaz.

Concebendo que a realidade educacional de uma universidade pública, como a UEFS, em que esse estudo se realizou, é uma realidade singular para a produção de autonomias reflexivas, é mister trazer à baila como tem sido desenvolvido os processos de relação pedagógica que professores e alunos tecem no cotidiano da docência universitária. Nesse sentido, pensar o processo de relação, focando, por um lado, na prática educativa de professores e, por outro, nas ações dos estudantes frente a tais práticas, emerge como relevante temática para se apreender mecanismos que evidenciem os modos como na docência universitária geram-se significativas produções de conhecimento.

Nesse sentido, e pelo recorte que foi possível realizar para a produção desse texto, em que se visibilizou o perfil socioidentitário e profissional dos professores, bem como as práticas educativas que estes desenvolvem nos momentos de planejar e avaliar o ensino e a aprendizagem dos estudantes, a pesquisa revelou dados significativos, que permitirá à própria comunidade acadêmica debruçar-se sobre os resultados e avaliar se de fato a relação professor e estudante se efetiva do modo como os resultados indicam, e se, por esta razão, se faz necessário engendrar esforços para que se continue gerando relações pedagógicas como as que aqui se conclui, ou se, por outro lado, é necessário promover mudanças em busca de criar sempre condições de possibilitar outros engendramentos nos processos relacionais entre professores e estudantes que se constroem na universidade.

O estudo permitiu visibilizar na amostra composta pelos 338 participantes, que o perfil identitário e socioprofissional dos docentes é caracterizado por uma maioria de homens brancos, do quadro efetivo da universidade e que atuam, em sua maioria, num regime de trabalho de dedicação exclusiva. São docentes que possuem, majoritariamente, idade superior a 46 anos, com destaque para um elevado número de profissionais com mais de 50 anos e com mais de 20 anos de atuação no magistério superior. Esses dados sinalizam que ainda impera na universidade a presença masculina, o que revela uma similaridade com o que se registra no censo do IBGE/2010, em que, na docência universitária, os homens ainda são maioria. Apesar de se evidenciar que na região nordeste, bem como no estado da Bahia, em se tratando do quantitativo de docentes que atuam nas universidades estaduais, a maioria do quadro é composto por mulheres, a Universidade Estadual de Feira de Santana ainda conserva similaridade com o cenário nacional, sobretudo no sistema público de ensino, em que os homens são a maioria. Isso indica a necessidade de ampliação de postos de trabalho e de democratização para o acesso às mulheres no âmbito dessa instituição.

De certo modo, os dados sugerem que mais de $90 \%$ dos professores estão em regime de dedicação exclusiva. Isso indica um elevado número de docentes que atuam apenas nessa instituição, com condições de se envolver integralmente nas ações que a universidade tem proporcionado. $O$ professor nesse tipo de regime tem maior condição de se dedicar as atividades de ensino, pesquisa e extensão universitária, favorecendo ampliações de situações e vivências dos estudantes na universidade, fato que possibilita ampliar as relações entre professor e estudante. Há ainda o fato de que são, em grande parte, professores do quadro efetivo, situação que gera condições de permanência desses profissionais, frente às demandas de se desenvolver projetos a longo prazo, facilitando e ampliando as relações acadêmicas com os estudantes.

No que tange aos aspectos inerentes ao planejamento educacional, o estudo permitiu concluir que os participantes realizam o planejamento e o apresentam aos estudantes. No entanto, não há indicativos de que os planejamentos pedagógicos ocorrem em função das dificuldades ou necessidades formativas dos estudantes. Poucos são os docentes que informam modificar o plano ou construir uma metodologia de ensino em função de atender às necessidades de aprendizagens dos estudantes. De igual modo, não é possível afirmar que a seleção 
de material para o ensino se efetive com base nas dificuldades dos estudantes, ainda que uma parcela de docentes informe que selecionam o material didático tendo em vista as dificuldades que os estudantes apresentam.

Com relação à avaliação da aprendizagem, os dados evidenciam que a avaliação é uma das preocupações dos professores, que informam discutir, com os estudantes, como serão caracterizados os instrumentos que comporão a avaliação da aprendizagem. Isso indica que a avaliação se assenta numa base dialógica, em que se nega a ideia de avaliar por aferir ou checar o desempenho dos estudantes. Assim, os dados evidenciam uma preocupação dos professores em comentarem as respostas nas avaliações, dando aos discentes um feedback sobre como tem sido o desempenho, com possibilidade de reorientar a sua própria prática, bem como orientar o estudante na perspectiva de desenvolver outras aprendizagens.

No entanto, é preciso considerar que este estudo, caracterizado por um questionário do tipo survey, em que se apresentou aos professores alternativas a fim que se escolha a resposta mais coerente ao seu fazer, é muito comum que se evidencie o que é positivo. Sobretudo em se tratando de uma escala do tipo Likert, em que as ocorrências podem sugerir elementos de positividade ou não nas práticas educativas. Isso posto, é relevante considerar que as respostas podem ter sido dadas com o objetivo de evidenciar os elementos positivos do fazer do professor, não indicando, necessariamente, que as práticas assim sejam efetivadas. Mas de algum modo, quando se toma a resposta que aparece nesse tipo de questionário, a contestação das afirmações não cabe ao pesquisador, se não analisar a luz do que os próprios dados sugerem. 


\section{Referências}

Ausubel, D. P.; Novak, J. D.; Hanesian, H (1980). Psicologia Educacional. Rio de Janeiro: Interamericana.

Brookhart, S (2008). How to give effective feedback to your students. Ed. ASCD. Virgínia.

Coulon, A (2008). A condição de estudante: a entrada na vida universitária. Salvador: Edufba.

Creswel, J. W (2007). Projeto de pesquisa: método qualitativo, quantitativo e misto. 2. ed. Porto Alegre: Artmed.

Instituto Brasileiro de Geografia e Estatística (2011). Censo Demográfico - 2010: Características da população e dos domićlíos. Resultados do universo. Rio de Janeiro: 2011. Recuperado de https://censo2010.ibge.gov.br/.

Libâneo, J. C. (2001). Organização e gestão escolar: teoria e prática. 4. ed. Goiânia: Alternativa.

Luckesi, C. C. (2005) Avaliaģão da aprendizagem escolar: estudos e proposições. 17. ed. São Paulo: Cortez.

Massi, L. (2013). Relação aluno-instituição: o caso da licenciatura do Instituto de Química da Unesp/Araraquara [Tese de Doutorado em Educação, Universidade de São Paulo].

Novak, J. D.; Gowin, B. D. (1996). Aprender a Aprender. Lisboa: Plátano Edições Técnicas.

Oliveira, D. d. A (2011). Gestão Democrática da Educação: Desafios Contemporâneos. $7^{\mathrm{a}}$ ed. Petrópolis: Vozes.

Pozo, J.I.; Mateos, M. (2009) Aprender a aprender: Hacia una gestión autónoma y metacognitiva del aprendizaje. In: Pozo, J.I.; Echeverría, M.P.P. Psicología del aprendizaje universitario: La formación en competencias. Madrid: Ediciones Morata.

Santos, C. P. d.; Soares, S. R. (2011) Aprendizagem e a relação professor-aluno na universidade: duas faces de uma mesma moeda. Est. Aval. Educ., 22 (49), 353-370. Recuperado de http://www.fcc.org.br/pesquisa/publicacoes/eae/arquivos/1641/1641.pdf.

Silva, F. O. da; Ribeiro, M. L.; Almeida, L. R. de M. (2018) A avaliação "é a bola girando na roda": reflexões sobre práticas avaliativas na universidade. Revista Internacional de Educação Superior, 4 (3), 664-684.

Teixeira, A. B. M. (Coord.) (2014). Mulheres na educação superior brasileira: estudo de caso sobre trajetórias acadêmicas e profissionais de mulheres em cursos de Física. Relatório de Pesquisa. Belo Horizonte: GSS/FAE/ UFMG. Agência Financiadora: CNPq.

Thurstone, L. L. (1928). Attitudes Can Be Measured. American Journal of Sociology, 33 (4), 529- 554.

Tinto, V. (2012). A theory of individual departure from institutions of higher education. In TINTO, V., Leaving college: rethinking the causes and cures of student attrition. Chicago: The University of Chicago Press, pp. 84137. 


\section{Sobre o Autor}

\section{FABRÍCIO OLIVEIRA DA SILVA}

(iD https://orcid.org/0000-0002-7962-7222

Pós-doutorando e Doutor em Educação e Contemporaneidade pela Universidade do Estado da Bahia - UNEB. Professor Adjunto da Universidade Estadual de Feira de Santana - UEFS, lotado no Departamento de Educação. Professor permanente do Programa de Pós-Graduação em Educação - PPGE/UEFS. Coordenador do Núcleo de Estudos e Pesquisas sobre Pedagogia Universitária - NEPPU. Líder do Grupo de Pesquisa Docência, Narrativas e Diversidade na Educação Básica - DIVERSO. Membro do GT 4 - Didática da Associação Nacional de Pesquisadores da Educação - ANPEd.

Email-fosilva@uefs.br

Currículo Lattes - http://lattes.cnpq.br/9101271365317978

Enviado em: 15 ago. 2020

Aprovado em: 23 nov. 2020. 